\title{
The role of information and communication technology in small Italian logistics enterprises
}

\author{
Pietro Evangelista \\ Institute for Service Industry Research (IRAT), \\ National Research Council (CNR), \\ Via M. Schipa 115, \\ Naples 80122, Italy \\ Fax: +39081 2470933 \\ E-mail: p.evangelista@irat.cnr.it
}

\author{
Edward Sweeney* \\ National Institute for Transport and Logistics (NITL), \\ Dublin Institute of Technology (DIT), \\ 17 Herbert St, \\ Dublin 2, Ireland \\ Fax: +353016611943 \\ E-mail: esweeney@dit.ie \\ *Corresponding author
}

\begin{abstract}
Information and communication technology (ICT) is widely regarded as a key integration enabler in contemporary supply chain configurations. Furthermore, recent years have seen the vertical disintegration of supply chains as increasing numbers of manufacturers and retailers outsource significant parts of their supply chain functionality. In this environment, third party logistics (3PLs) providers - the majority of which are small companies play a pivotal role. This raises important questions about the usage of ICT in this sector. However, there is a paucity of research in the field of small 3PLs with little empirical investigation into the usage of ICT by such firms. This article presents the results of a survey on ICT systems usage in a sample of small Italian 3PLs. The results provide a technological profile of the surveyed companies as well as an analysis of the role of ICT in customising services and of the factors influencing technology adoption.
\end{abstract}

Keywords: competitive advantage; empirical survey; ICT; information and communication technology systems usage; information system integration; Italian logistics service market; small logistics service providers; supply chain.

Reference to this paper should be made as follows: Evangelista, P. and Sweeney, E. (2009) 'The role of information and communication technology in small Italian logistics enterprises', Int. J. Business and Systems Research, Vol. 3, No. 1, pp.1-18.

Biographical notes: Pietro Evangelista is a Researcher in Logistics and Supply Chain Management at the Institute for Service Industry Research (IRAT) of the Italian National Research Council (CNR) based in Naples. His research interests include supply chain management in small manufacturing companies and shipping logistics. Currently, his scientific activity is focused on diffusion of information technology innovation in the logistics service industry. This is reflected in several papers and articles published in national and international journals as well as chapters in books. He is a Lecturer in Business Economics at the Faculty of Engineering of the Naples' University Federico II.

Edward Sweeney is a Director of Learning at the National Institute for Transport and Logistics (NITL) in Dublin, Ireland. NITL, based at the Dublin Institute of Technology, is Ireland's centre of excellence in logistics and supply chain management. His research interests are in supply chain strategy development and implementation. He has published over 80 books, papers and reviews, and has worked and lectured in over 20 countries in Europe, North America and Asia. A 
Mechanical Engineer by background, he has held academic appointments at the Trinity College Dublin, the University of Warwick and the University of Technology, Malaysia.

\section{Introduction}

In recent years, there has been a growing recognition of the strategic role of the supply chain management (SCM) concept in a variety of business sectors. For the purposes of this article, SCM is regarded as being fundamentally concerned with the strategic coordination of activities both within firms and between firms across the wider supply chain (Mentzer et al., 2001).

It is widely recognised that information and communication technology (ICT) plays a key role in effective SCM (Christopher, 1992; Simchi-Levi and Kaminsky, 2003; Van Hoek and Harrison, 2004). The shift from traditional supply chain configurations, often characterised by fragmentation, to more coordinated and integrated approaches is central to SCM. This emphasis on integration puts ICT at the heart of contemporary approaches to the subject. Furthermore, the globalisation of supply chain architectures requires that information is shared and managed internationally. In this context, it is recognised thatICT is becoming a key enabler of SCM (see, for example, Lee and Whang, 2000).

The application of the SCM concept also leads manufacturers and retailers to outsource significant parts of their supply chain functionality to external organisations. This is particularly, the case in relation to transportation and logistics activities (McKinnon, 1999). As part of this process, there is a trend to select a relatively small number of logistics providers with which to establish long-term relationships for the supply of 'tailor-made' services (Razzaque and Sheng, 1998). Thus, logistics companies are playing a more important role than in the past as they coordinate and accelerate physical and information flows along multiple levels of the supply chain (Cooper, Lambert and Pagh, 1998). Indeed, in keeping pace with rapid market changes, the whole logistics system has become more efficient and flexible. This has forced third party logistics (3PLs) to look for accurate and real-time information on the status of the entire shipment process to increase their planning capacity and to improve customer service levels (Stough, 2001).

Nevertheless, the use of ICT in the 3PL sector is unevenly distributed between large, small and medium-sized logistics service providers1. For example, a most recent report published by the Italian Minister of Technology Innovation (2004) indicated that large Italian companies (representing approximately $0.5 \%$ of the total number of Italian companies) have a share of $80 \%$ of the total ICT expenditure at national level, while small companies (representing approximately 95\% of the total number of Italian companies) invested the remaining $20 \%$.

Large logistics firms have heavily invested in ICT and have actively developed information systems and applications (for example, UPS recently established a department in Atlanta entirely dedicated to software development to support customer operations). Furthermore, they have been using inhouse information systems to support their operations for a long time. Small logistics service providers, on the other hand, have more difficulties in setting up ICT applications due to insufficient human, financial and organisational resources. This has further complicated the competitive position of small logistics service providers - it seems that they have underestimated the potential of ICT as an enabler for increasing cost-efficiency and improving customer service. The real riskis that small 3PLs could either be marginalised in the marketplace as 'tier suppliers' of large logistics companies or even forced out of the market completely. The scenario that might arise could present small 3PLs with two different alternatives: survive in a low cost world of transportation carriers (commodity providers) or pursue the expensive and problematic path of becoming value adding providers through innovation in technology and in other aspects of their operation (advanced logistics providers). This situation appears particularly critical in those markets characterised by a large number of small 3PLs and where multinational logistics companies hold a substantial market share as in the case of the Italian 3PL industry. 
From a research point of view, while information technology in large 3PLs has been widely investigated (Peters et al., 1998; Berglund et al., 1999; van Hoek, 2000; Larson and Gammelgaard, 2001), the existing studies have seldom focused on small logistics service providers (Gunasekaran and Ngai, 2003) with little empirical survey analysing the adoption of ICT by these companies (Kilpala et al., 2005; Pokharel, 2005). The limited number of studies available give rise to the need to develop further research in order to acquire a deeper understanding and in-depth knowledge on how the level of technology capability of small logistics companies may affects the customisation of service provided and improve the competitive abilities of these companies (Maloni and Carter, 2006).

The study described in this article attempts to fill this void through an empirical investigation developed on a sample of small Italian logistics service providers. The survey is aimed at analysing ICT usage in the sector and at identifying the main factors affecting technology adoption. The integration-enabling role of ICT is a key focus of the study.

Following this introduction, the nature of supply chain vertical disintegration is described (Section 2). An overview of the Italian logistics service market is provided and an analysis of information technology usage by Italian 3PL companies (Section 3). Section 4 goes on to describe the research approach used to investigate ICT usage in a sample of 153 small Italian logistics companies through a mail survey. The main research findings are then presented in Section 5. Section 6 discusses the managerial and research implications of the survey.

\section{Supply chain vertical disintegration}

Companies are increasingly focusing on what they regard as their core activities or competencies. Oates (1998) defines 'core competencies are those activities central to an organisation's strategy which firms do well'. The corollary of this is that activities regarded as 'non-core' can be outsourced. Furthermore, the trend towards economic and business globalisation has facilitated the outsourcing of various activities to overseas locations. These changes have resulted in a shift away from the traditional model of control through ownership towards models which are based on management and control through effective supply chain relationship management. The former is based on the strategic logic of vertical integration.

Vertical integration is the degree to which a firm owns its upstream suppliers and its downstream buyers (Greaver, 1999). Harrigan2 (2003) provides a good description of the logic underpinning this approach to strategic development. Recent developments in ICT in particular internet technologies have facilitated this process and laid the foundations for the 'network economy model' (Reddy and Reddy, 2001). According to Hugos (2002, p.235), traditional supply chain models have 'given way to virtual integration of companies'. In short, as outsourcing of various elements of supply chain functionality takes place so, supply chain architectures are becoming more virtual. The traditional fully vertically integrated (FVI) approaches are being replaced by contemporary fully virtually integrated approaches - a new FVI is evolving. The focus of this study is on the 3PL organisations to whom as noted earlier, a wide variety of transportation and logistics activities are being outsourced. The advantages and disadvantages of vertical control in the logistics service industry have been studied extensively by Heaver (2002, pp.215-218) with specific reference to shipping and logistics. The main advantages associated with vertically integration relate to the creation of demand complementarity, the achievement of cost reductions and the creation of synergies through the shared use of expertise. The disadvantages relate mainly to barriers to the achievement of sustainable relationships between companies, often as a result of cultural differences.

In this environment, ICT is a central element for the development of logistics services in a customised supply chain context. Sauvage (2003) noted that information technology capability is a critical variable for logistics service differentiation in today turbulent industry scenario characterised by time compression and flexibility. Van Hoek (2002) assigned a specific role to ICT 
for 3PLs aiming to perform customising operations for service users. The author pointed out that the use of specific technological capabilities may leverage transport and logistics services, and facilitate more effective integration across companies in the supply chain. For 3PLs, ICT capabilities can assure the rapid customisation of services and maintain competitive lead-times. The result is that competitive advantage in the 3PL industry will be based increasingly on creating value for customers, as many value added activities are directly or indirectly dependent on ICT applications (Crowley, 1998).

\section{Information and communication technology usage in the Italian logistics service market}

This section provides an overview of some of the key characteristics of the Italian logistics service provision market. It goes on to present evidence from the limited number of studies of ICT usage which has been carried out to date in the sector.

\subsection{Overview of the main features of the Italian logistics service industry}

The Italian 3PL market reflects the vertical disintegration of supply chains which is taking place. Several sources estimate that in 2001, it was the fifth largest European market with the highest expected growth rate in Europe in coming years (Harvey, 2003). In the same year, the total value of logistics outsourcing was approximately $€ 12 \mathrm{bn}$ ( $3.6 \%$ of the Italian gross national product).

The most recent data estimate the number of firms in the sector between 140,000

(Confetra 3) and 205,000 (Unioncamere 4). These data indicate that one of the main characteristics of the Italian market is its high fragmentation. For example, a recent analysis carried out by an Italian logistics magazine, Il Giornale della Logistica (June/July 2004, p.48), on a sample of 1,000 Italian 3PLs ranked by turnover shows that: 1 the largest 100 companies (i.e. $10 \%$ of the total) produce $64 \%$ of the total sample turnover 2 for the largest 200 companies (i.e. $20 \%$ of the total), the percentage is $75 \%$.

The fragmentation of the market is also evident when considering employee data. According to a recent KPMG report (2003), about 50\% of Italian logistics providers employ less than 50 people and that $35 \%$ of them employ less than nine people. This fragmentation of the Italian logistics service industry has facilitated the entry of large multinational logistics groups in recent years.

\subsection{Evidence of information and communication technology usage}

As noted earlier, in the context of vertically disintegrating supply chain configurations, manufacturers and retailers are demanding a higher degree of integration of the business processes of all supply chain participants through ICT and internet technologies. As a result, 3PLs are devoting increasing importance to ICT in the management of their businesses and ICT is fast becoming one of the main drivers of change, posing new strategic challenges to logistics providers. Although ICT development has strongly affected the logistics service industry in recent years, a number of surveys over the last decade have confirmed that the adoption of new technologies in the Italian logistics service market has been relatively low (CSST and Cranfield University, 2002; Freight Leaders Club, 2003; KPMG, 2003). For example, the work of Merlino and Testa (1998) highlighted that the dissemination of new technologies is proceeding at an intermittent and nonhomogeneous pace. Investments in new technology are still motivated by a tactical rather than a strategic logic. This can be mostly attributed to the history of the particular firm under study and its entrepreneurial culture.

The results of the above studies raise a number of important issues. Vertical disintegration has resulted in 3PLs playing an increasingly pivotal role in terms of overall supply chain capability. This capability is largely a product of the levels of integration built into supply chain architectures. As noted earlier, these levels of integration are dependent upon the effective utilisation of appropriate ICT tools. Despite this potentially important role of ICT in improving the competitive capability of 3PLs, there appears to be a limited level of ICT adoption with particular reference to 
the internet and electronic business tools. This points to the need to develop new insights into actual practice in this area. The research described in this article aims to contribute to the development of these insights.

\section{Research design and methodology}

New technology is reshaping the organisation and structure of this industry as ICT impacts significantly on the operations of 3PLs. 3PLs are gradually shifting from an asset-based offer to a more process-oriented approach largely based on knowledge and information management. While there is evidence to suggest that large 3PLs are gaining substantial benefits from technology usage and implementation, the nature of changes resulting from ICT usage in small logistics service providers remains unclear. Given the predominance of small 3PLs, and their increasingly critical role in the context of overall supply chain effectiveness, this gives rise to the need to develop research and investigation in order to acquire a deeper understanding and in-depth knowledge regarding the level of technology capability and the effects of new technologies on the competitive abilities of these companies. This is particularly critical for the European

Union logistics service market that is characterised by the strong presence of small logistics service companies 5 (Evangelista and Kilpala, 2007). Consequently, the Italian logistics service market appears a suitable context for this research.

This research seeks to narrow the knowledge gap in the field of ICT adoption in small 3PLs through an empirical investigation. The aim of the survey is to provide an overview of ICT adoption in small logistics service providers in the context of overall supply chain integration and performance. The specific objectives are as follows:

1 to set-up a technological profile of the surveyed companies

2 to analyse the role of ICT tools in supporting the customisation of services

3 to analyse factors influencing the adoption of ICT.

The survey methodology was organised into the following seven steps:

1 Definition of basic survey objectives and preparation of the draft questionnaire.

2 Establishment of focus groups. Seventeen key influencers (ICT managers of small 3PLs, ICT consultants, directors of Italian logistics associations, researchers and academics) were involved in two focus group meetings. The main aim was to submit the basic survey objectives and draft questionnaire in order to get useful feedback from participants and to test the suitability and comprehensibility of the questionnaire. A further aim was to gain 'buy-in' from relevant trade associations in administering questionnaires through the use of their mailing lists and their logos.

3 Re-focussing of survey objectives and questionnaire. Based on the focus group results, this step enabled a better focus on the survey objectives and obtained useful inputs in finalising the questionnaire. The final questionnaire contained 37 questions divided into four sections.

4 Population definition. A recent study indicates that the implementation of ICT systems for transport management can be commercially justified only for companies operating more than five vehicles (McClelland and McKinnon, 2004). This issue has been confirmed by a recent survey conducted specifically on ICT usage in a sample of small road hauliers operating in the South of Italy. The test of questionnaire conducted with key actors (such as, managers of road haulage companies, ICT consultants, representatives of Italian road transport associations, etc.) in a panel meeting, evidenced that investment in ICT is not a priority for such companies as the small number of trucks they own may be effectively managed through technology like mobile phones (see Evangelista, Marasco and Caiazzo, 2005).

For the purposes of the research, therefore, the total population has been narrowed to exclude very small providers that are marginal in the context of the wider supply chain. Considering the Confetra's most recent estimate (2004), the number of Italian logistics service companies is 140,550. This figure is based on a segmentation of the Italian logistics service market that comprises five segments. There are no fourth-party logistics operating in the market, while 50 
companies are operating in the lead logistics providers segment as branches of large multinational logistics groups or logistics spin-offs of both large Italian and multinational manufacturing companies. The number of companies populating the 3PLs providers segment is estimated at around 500. These are small- and medium-sized Italian companies mainly specialised on market niches. The road haulage segment comprises 140,000 companies and has been divided into two categories in line with the criteria detailed above (more or less than five trucks) on the basis of Albo Nazionale Autotrasportatori (Italian road hauliers registry) data. Road haulage companies owing more than five trucks are estimated at about 21,000 companies while road haulage companies owing less than five trucks are 119,000. Considering the subject (ICT usage)and the scope (Italian small and medium logistics service companies) of this research, only the 3PL segment and the road haulage companies owing more than five vehicles have been considered. Based on this, the total population in this research is estimated at approximately 21,500 companies.

5 Preparation of the mailing list. There is a low level of consistency and quality of data and information about logistics companies operating in the Italian market, as a result of the plethora of different sources. For this reason, company information was obtained from several sources - partly from the Italian logistics associations that took part in the focus groups and partly from other sources (including logistics magazine subscribers and transport electronic-marketplace databases). A draft mailing list containing 2,464 records (companies) was obtained from these sources.

Each individual record was checked to ensure that companies selected were in line with the criteria on which the population has been defined. A number of inconsistencies was detected, and this reduced the total number of companies included in the survey from 2,464 to 1,992. More information regarding population definition is provided in Section 5.

6 Survey implementation. The questionnaire was mailed to 1,992 companies throughout Italy. The total number of usable responses was 153 . Furthermore, to ensure data reliability and completeness, respondents were subsequently contacted by e-mail and telephone in order to clarify unclear responses or to add missing data. To detect any possible non-response bias, a two steps analysis has been carried out. Firstly, a sub-sample of non-respondents were contacted to get responses about some demographic characteristics (such as company age, company size and type of activity) to be compared with respondents. This step did not indicate any significant bias. In a subsequence step, the method adopted by Goode and Stevens (2000) was used. This method involves comparing later respondents with earlier respondents, assuming that later respondents may possess similar characteristics to non respondents.

Accordingly, the usable responses were split into two sets, respectively of 76 and 77 responses based on the dates on which they were received. A Mann-Whitney and $\chi^{2}$ analysis of the above three variables revealed insignificant differences between the two groups of companies.

7 Sample classification. Within the population, a taxonomy is proposed based on the following three categories:

1 Full haulage providers. Those companies for which transport activities represent $100 \%$ of turnover.

2 Basic logistics providers. Those companies for which transport and warehousing together comprise over $50 \%$ of turnover.

3 Advanced logistics providers. Those companies for which transport and warehousing together comprise less than $50 \%$ of turnover (i.e. where more than $50 \%$ of the total turnover is generated by value added logistics and SCM services).

Table 1 shows a breakdown of the sample firms by provider type according to the above classification criteria.

Table 1 Sample firm classification 


\section{Findings}

In this section, a summary of the results of the empirical investigation are presented. Following an overview of the sample characteristics, the section documents and discussesthe survey results for each research objective set out earlier.

\subsection{Sample characteristics}

Figure 1 provides a breakdown of the respondents by the main Italian geographical areas. The majority of the sample firms are located in the northern part of the country $(76.5 \%)$ - this reflects the high concentration of economic activity in that area. Figure 2 shows the number of value added services offered beyond transport and warehousing by the surveyed companies. Moving from full haulage to advanced logistics providers, the number of value added services offered increases dramatically. This supports the validity of the classification criteria adopted in this study.

\section{Figure 1 Sample firms by geographic area}

\section{Figure 2 Value added services supplied beyond transport and warehousing}

\subsection{Technological profile of the surveyed company}

The following set of data describe the technological profile of the surveyed companies. Figure 3 provides a summary of total ICT costs (hardware, software, employees, and consultancy and communication costs) as a percentage of total company costs in 2003. Of the 100 companies that responded to this question, 36 spent less than $1 \%$ of their total costs on ICT. Eleven companies spent more than $10 \%$ of their total costs on ICT. Figure 4 illustrates the various ICT tools that the three provider types currently adopt in their relationships with both customers and other logistics providers.

\section{Figure 3 Percentage of information and communication technology costs on total company costs (2003)}

\section{Figure 4 Current information and communication technology usage by provider types}

The data indicates a low level of usage of relatively sophisticated technologies among all provider types, particularly in the management of relationship with customers (e.g. ERP and CRM). The figure clearly shows that moving from full haulage to advanced logistics providers, the use of more sophisticated technologies increases significantly.

However, given that global positioning system is an emerging technology, it is relatively widely used in full haulage providers $(38.9 \%)$. This is perhaps not surprising given the importance of satellite navigation in purely transport businesses. Nonetheless, a significant majority $(61.1 \%)$ still do not make use of this technology.

All providers use telephone, fax, mobile, internet and e-mail to a great extent. In relation to other ICT tools, more than half of both basic and advanced logistics providers use EDI (52.2 and 62.5\%, respectively) with similar numbers using LAN (47.8 and $68.8 \%$, respectively). The usage of these technologies is quite low for full haulage providers (19.4\% for EDI and 38.9\% for LAN). Though the adoption of more complex technologies (such as Wireless LAN, RFID, ERP and CRM) is quite low in all firms, data show that these technologies are more widely used by advanced logistics providers.

\section{Table 2 Overall information system supply chain integration}

Table 3 Information systems integration 
Table 2 describes the degree of overall information system integration in the supply chain for different types of provider. The analysis was built up using a scoring model linking information system integration to different supply chain participants (customer, customer's customers, suppliers and other 3PLs). The scale was based on $0=$ no information system integration, $1=$ partial information system integration and $2=$ full information system integration. The scores for each of the four supply chain participants were added. Consequently, the highest level of supply chain integration achievable is equals to eight. The values included in the table represent the average value of information system integration in the supply chain for each provider type. The degree of information system integration in the supply chain is quite low overall. Nevertheless, data reported in the table reveal that advanced logistics providers have a significantly higher degree of information system integration $(p=0.9 \% ; F=4.86) 6$.

A more detailed analysis of information system integration is given in Table 3. These data confirm that most providers have no integration with other supply chain participants $(85.9 \%)$. The data indicate a significant difference among the types of provider as in the case of advanced logistics, which have the highest number of companies fully integrated in comparison with full haulage and basic logistics ( $p=4.8 \% ; \square 2=9.58$ ).

\subsection{The role of information and communication technology tools in supporting the customisation of service}

Amongst the most important of the available ICT applications used in the customisation of logistics services, these tools are websites. Effective use of this tool provides the potential to simultaneously reduce costs and improve customer service. Based on the entire sample, it emerges that 105 companies $(68.6 \%)$ have a website in place, while 48 companies $(31.4 \%)$ do not. The level of company website adoption across the different provider types is $61.1 \%$ for full haulage; $71.6 \%$ for basic providers and $72.9 \%$ for advanced providers. This suggests that this technology is well reasonably established within Italian small logistics providers. Considering website adopters, data shown in Figure 5 reveal that the most important functionality associated with website usage is in the areas of electronic service catalogues, company presentation and advertising channels. This means that adopters are not very innovative in the use of their website. In fact, according to the KPMG, electronic-commerce business maturity model (Ellinger et al., 2003), this evidence confirms that the surveyed companies are still in the early stage of the model (basic marketing and publishing). Figure 6 shows the reasons cited for non adoption of websites. The main reasons are:

- website deemed unnecessary for their businesses

- customers do not require internet services

- website start-up costs.

These results suggest that companies underestimate the potential value of websites in improving their businesses and as an instrument to customise the services supplied.

\section{Figure 5 Importance of website functionality}

\section{Figure 6 Reasons for non-website adoption}

\subsection{Factors influencing the information and communication technology adoption}

In this section, an overview of the main factors influencing the adoption of ICT in the sample firms is provided. Firstly, the survey analysed the factors that stimulate the use of

ICT in the sample firms (see Table 4).

The most significant difference emerges with reference to the improvement of information exchanged with supply chain participants (namely customers and logistics providers). Advanced logistics providers attribute a higher importance to this factor in comparison with basic logistics and full haulage companies ( $p=1.2 \%, F=4.56)$. A significant difference also exists with reference to 
the improvement of customer satisfaction $(p=14.8 \%, F=1.92)$ and to the enlargement of customer base ( $p=12.0 \%, F=2.13)$.

The data shown in Table 5 provide details about the importance of future investment areas in ICT by different provider types. The importance attributed to different ICT areas of investment has been measured on a scale where zero indicated 'no importance' and three 'very important'. It is interesting to note that only $14 \%$ of full haulage (five companies) scored three, while basic logistics and advanced logistics show higher percentages (42\% with 28 respondents and $44 \%$ with 22 respondents, respectively).

Table 5 shows the areas for future ICT investment considered 'very important' for respondents. Technology investment for improving competitiveness and error reduction are the most important areas for all three types of providers. The area of error reduction is considered of particularly high priority for basic logistics companies. Improving integration with customers is critical only for basic and advanced companies. Full haulage and basic logistics companies attribute importance to future technology investment for developing service differentiation. The above data suggest that full haulage companies have a limited interest in developing future ICT investment in comparison with other two types of providers.

\section{Table 4 Factors stimulating information and communication technology usage}

\section{Table 5 Areas for future information and communication technology investment considered}

\section{Figure 7 Factors inhibiting information and communication technology adoption}

With regard to the factors inhibiting ICT adoption in the sample firms, significant differences do not emerge between the provider classifications. The results in Figure 7 provide an interesting picture. The most important reasons for non-investment in ICT are related to financial factors.

\section{The role of ICT in small Italian logistics enterprises 15}

The size of investment and the implementation costs together with running costs are considered the most influential factors inhibiting ICT investment. Human resources management and ICT supply side also play a non-marginal role in inhibiting ICT expenditure. In order to understand the state of ICT penetration in the small logistics companies, it is interesting to examine two recent studies. The first study was carried out by Kilpala et al. (2005) on a sample of 168 small 3PLs located in the Barents region that comprises the Northern parts of Finland, Norway and Sweden, and the northwestern part of Russia. The second survey was conducted by Pokharel (2005) on a sample of 45 small 3PL companies operating in the Singapore logistics service market. In both studies, it is clear that the focus of firms is on internal efficiency improvement through cost reduction while increasing customer service levels plays a secondary role in stimulating ICT investment. With regard to barriers to ICT investment, the two studies show strong similarities. The Nordic study put in evidence that the main barriers are as follows:

1 lack of awareness of ICT benefits

2 investment costs (lack of funds)

3 lack of technological skills (insufficient training, lack of ICT specialists).

For the Singapore 3PLs, the main inhibitors are:

1 lack of adequate ICT resources

2 problems in quantifying intangible benefits (such as better coordination, increased variety and innovation)

3 integration with current policies

4 higher costs

5 anticipated time required for full implementation of ICT. 


\section{Concluding comments}

The survey results indicate that the use of relatively advanced ICT is more prevalent in advanced providers. This is particularly the case in relation to the level of information system integration and the exchange of information with other supply chain participants. This is significant in the context of supply chain vertical disintegration and the increasingly important role being assumed by 3PLs in the wider supply chain. Despite the fact that current levels of expenditure on ICT in relation to overall company cost base do not vary significantly across provider categories, there are significant differences with regard to future investment plans. This is particularly true in the area of integration with both customers and other 3PLs. This suggests that the focus on integration is stronger in advanced providers with a longer term and strategic view being adopted. This may accentuate the trend of the less developed providers being marginalised in the evolving competitive landscape.

The competitive landscape for small 3PLs is continuously changing to reflect evolving customer requirements and other business pressures. The capability of emerging ICT is increasing at a rapid rate and its effective adoption has the potential to enhance significantly the competitive capability of small 3PLs. However, it is clear that many barriers exist to the successful adoption of ICT by these providers. Furthermore, the role of ICT as an integration enabler in increasingly vertically disintegrating supply chain architectures is a source of concern. Given the importance of small 3PLs in contemporary supply chain configurations, it is likely that they will quickly become the weak links unless their ICT capability is enhanced. In conclusion, if the full potential of ICT as an integration enabler is to be exploited, then it is important that these issues are more fully understood. The authors' ongoing research is aimed at developing this understanding.

\section{References}

Berglund, M., van Laarhoven, P., Sharman, G. and Wandel, S. (1999) 'Third party logistics: is there a future?', Int. J. Logistic Management, Vol. 10, pp.59-70.

Christopher, M. (1992) Logistics and Supply Chain Management. London, UK: Pitman Publishing.

Cooper, M.C., Lambert, D.M. and Pagh, J.D. (1998) 'What should be the transportation provider's role in supply chain management?', Paper presented in the Proceedings of the 8th World Conference on Transport Research, 12-17 July, Antwerpen, Belgium.

Crowley, A.G. (1998) 'Virtual logistics: transport in the marketspace', Int. J. Physical Distribution and Logistics Management, Vol. 28, pp.547-574.

CSST (2002) 'Centro Studi sui Sistemi di Trasporto and Cranfield University', Transport and

Logistics in the Digital Era: A Survey of Telematic Use by European Road Freight Operators,

Survey Report, Fiera di Genova, October 28-29, Genoa, Italy.

Ellinger, A.E., Lynch, D.F., Andzulis, J.K. and Smith, R.J. (2003) 'B-to-B E-commerce: a content analytical assessment of motor carrier websites', Journal of Business Logistics, Vol. 24, pp.119220.

Eurostat (2003) Panorama of Transport - Statistical Overview of Transport in the European Union, 1970-2001 - Part 2. Luxembourg. Office for Official Publications of the European Communities, pp.47-49.

Evangelista, P. and Kilpala, H. (2007) 'Perception on ICT usage in small logistics service providers: a comparison between North and South Europe', European Transport/Trasporti

Europei, special issue 'Pan-European Logistics and Supply Chain Challenges: Setting the

Research Agenda', pp.81-98.

Evangelista, P., Marasco, A. and Caiazzo, M. (2005) 'ICT adoption in a fragmented industry: evidences from the road haulage sector', Paper presented in the Proceedings of the Logistics Research Network Annual Conference International Logistics and Supply Chain Management, 79 September, Plymouth, UK, pp.139-146.

Freight Leaders Club (2003) Flussi Informativi Nel Trasporto Merci e Nella Logistica. Criticità, Stato Dell'arte e Proposte. Quaderni No.14, Milan, Italy (in Italian). 
Goode, S. and Stevens, K. (2000) 'An analysis of the business characteristics of adopters an non adopters of WWW', Technology Information and Management, Vol. 1, pp.129-154.

Greaver, M.F. II (1999) Strategic Outsourcing - A Structured Approach to Outsourcing Decisions and Initiatives. New York, NY: Amacon.

Gunasekaran, A. and Ngai, E.W.T. (2003) 'The successful management of a small logistics company', Int. J. Physical Distribution and Logistics Management, Vol. 33, pp.825-842.

Harrigan, K.R. (2003) Vertical Integration, Outsourcing, and Corporate Strategy. New York, NY: Beard Books.

Harvey, J. (2003) 'Where is the 3PL industry heading - trends, threats and opportunities? Tibbett and Britten: a case study', Presentation given at the Eyefortransport 3PL Summit, 14th

October, London, UK.

Heaver, T.D. (2002) 'The evolving role of shipping lines in international logistics', Int. J. Maritime Economics, Vol. 4, pp.219-225.

Hugos, M.H. (2002) Essentials of Supply Chain Management. London, UK: Wiley

Italian Minister for Technology and Innovation (2004) 'Innovation and digital technology', Research Centre of the Italian Minister for Technology and Innovation, pp.98-99 (in Italian).

Kilpala, H., Solvang, W.D., Widmark, J., Bagaeva, A. and Tuohinto, P. (2005) 'Analysis of ICT use in the Barents region: research findings from logistics service providers and forest industry', Sustainable Transport in the Barents Region (STBR), Publications 11/2005, ISBN 952-5549-18-6. Available at http://www.barentsinfo.fi/stbr/ (accessed 18.12.2007)

KPMG (2003) 'Logistica integrata ed operatori di settore: trend e scenari evolutivi del mercato Italiano', KPMG Business Advisory Services, Milan, Italy.

Larson, P. and Gammelgaard, B. (2001) 'Logistics in Denmark: a survey of the industry', Int. J. Logistics: Research and Applications, Vol. 4, pp.191-205.

Lee, H.L. and Whang, S. (2000) 'Information sharing in a supply chain', Int. J. Technology Management, Vol. 20, pp.373-87.

Maloni, M.J. and Carter, C.R. (2006) 'Opportunities for research in third party logistics?', Transportation Journal, Spring, Vol. 45, pp.23-38.

McClelland, D. and McKinnon, A. (2004) Use of Vehicle Telematics Systems for the Collection of Key Performance Indicator Data in Road Freight Transport. Heriot Watt University, UK, p.4.Available at: www.sml.hw.ac.uk/logistics

McKinnon, A. (1999) 'The outsourcing of logistical activities', in D. Waters (Ed.), Global Logistics and Distribution Planning. London, UK: Kogan Page, pp.215-234.

Mentzer, J.T., DeWitt, W., Keebler, J.S., Min, S., Nix, N.W., Smith, C.D. and Zacharia, Z.G. (2001) 'Defining Supply Chain Management', Journal of Business Logistics, Vol. 22,

pp.1-25.

Merlino, M. and Testa, S. (1998) 'L'adozione delle tecnologie dell'informazione nelle aziende fornitrici di servizi logistici dell'area genovese-savonese: risultati di un'indagine empirica', Paper presented in the Proceedings of the 2nd Workshop I Processi Innovativi Nella Piccola Impresa, 21-22 May, Urbino, Italy.

Oates, D. (1998) Outsourcing and Virtual Organisation - The Incredible Shrinking Company. London, UK: Century Business.

Peters, M., Cooper, J., Lieb, R.C. and Randall, H.L. (1998) 'The third-party logistics industry in Europe: provider perspective on the industry's current status and future prospects', Int. J.

Logistics: Research and Applications, Vol. 1, pp.9-25.

Pokharel, S. (2005) 'Perception on information and communication technology perspectives in logistics - a study or transportation and warehouse sectors in Singapore', The Journal of Enterprise Information Management, Vol. 18, pp.136-149.

Razzaque, M.R. and Sheng, C.C. (1998) 'Outsourcing of logistics functions: a literature survey', Int. J. Physical Distribution and Logistics Management, Vol. 28, pp.89-107.

Reddy, R. and Reddy, S. (2001) Supply Chains to Virtual Integration. London, UK: McGraw-Hill. 
Sauvage, T. (2003) 'The relationship between technology and logistics third-party providers', Int. J. Physical Distribution and Logistical Management, Vol. 33, pp.236-253.

Simchi-Levi, D. and Kaminsky, P. (2003) Managing the Supply Chain: The Definitive Guide for the Business Professional. New York, NY: McGraw-Hill.

Stough, R.R. (2001) 'New technologies in logistics management', in A. Brewer, K.J. Button and D.A. Hensher (Eds), Handbook of Logistics and Supply Chain Management, Elsevier Science, p.517.

van Hoek, R. (2000) 'The role of third-party logistics providers in mass customization', Int. J. Logistics Management, Vol. 11, pp.37-46.

18 P. Evangelista and E. Sweeney

van Hoek, R. (2002) 'Using information technology to leverage transport and logistics service operations in the supply chain: an empirical assessment of the interrelation between technology and operation management', Int. J. Information Technology and Management, Vol. 1, pp.115130.

van Hoek, R. and Harrison, A. (2004) Logistics Management and Strategy. London, UK: FT Prentice Hall.

\section{Notes}

${ }^{1}$ In this article, the European Union definition of small and medium enterprises has been adopted. According to this definition, firms with less than 10 employees (and a turnover of $€ 2$ million) ar considered 'micro', firms whose employees range from 10 to 50 (and a turnover of $€ 10$ million) are 'small', while firms employing less than 250 people (and a turnover of $€ 50$ million) are considered 'medium'. For further details, see Recommendation 2003/361/EC.

${ }^{2}$ Professor Harrigan of Columbia University presents a conceptual model based on four dimensions: breadth, stages, degree and form, based on analysis of data from 16 industry sectors and the integration actions of 192 companies.

${ }^{3}$ Confederazione Generale Italiana dei Trasporti e della Logistica (Confetra) is the largest Italiantransport and logistics association.

${ }^{4}$ Unione delle Camere di Commercio (Unioncamere) is the Italian federation of chambers of commerce.

${ }^{5}$ See Eurostat (2003) Panorama of Transport. Statistical overview of transport sector in the European Union.

${ }^{6}$ The letter ' $p$ ' is associated with a statistical test indicating the probability of accepting the hypothesis formulated and rejecting the null hypothesis. The smaller the $p$ value, the more strongly the test rejects the null hypothesis. The letter ' $F$ ' indicates the $F$-test for the analysis of variance. The objective of this tool is to test the null hypothesis and assumes that the population is normally distributed and that samples are independent of each other. 